better nurse, however, the question should be whether there is evidence that it makes a less efficient one. Perhaps the new UK Central Council for Nursing, Midwifery, and Health Visiting (due to come into existence later this year) could consider issuing some wellinformed advice to schools of nursing with regard to this and similar questions. The CMB did this sometime ago, but while I would disagree with some of its recommendations (for example, with regard to epilepsy it would seem sensible for them to be in line with the legal requirements for application for a driving licence) it was a step in the right direction. Such advice would, hopefully, help to dispel some of the prejudice which obviously now exists and the resultant situation in which some schools of nursing appear to be doing their own, maybe subconscious, medical screening, in addition to their selection of suitable candidates.

MARgaret Hughes

Occupational Health Service,

South Glamorgan Health Authority (T),

University Hospital of Wales.

Cardiff C4 4XW

SIR,-Miss H K E Browning's letter (26 July, p 307) about careers for diabetic girls in nursing makes sad reading. I believe that, just as nurses are often the best judges of a doctor's competence, doctors know a lot about what makes a good nurse; and instead of defending our separate territories in the spirit of professional apartheid we should be using our complementary experience of medical practice in choosing the best candidates for both professions. I would certainly welcome a nursing colleague in the task of selecting medical students and residents and I believe that nursing should be represented as of right on the GMC. Moreover, I am an advocate of a year's nursing experience as an essential qualification for entry to medical school alongside the requisite academic achievements.

It is my view that given two candidates for medicine or nursing the one with personal experience of what it is like to be on the receiving end of medical care should be given preference; and the same argument might well be applied to our choice of receptionists, telephonists, porters, and other ancillary workers. Such a policy would help to make hospitals the therapeutic communities which at present they are not, either in spirit or in structure. Professional status is conferred for the sake of the clients not the workers, whose privileges are granted in order to make it easier for them to discharge their responsibilities.

\section{J A Davis}

University Department of Paediatrics, Addenbrooke's Hospital,

\section{Generic prescribing}

SIR,-In your issue of the (19 July, p 230) Dr B Jarman reiterated the savings that could be made through prescribing drugs by their generic names, and Dr G P Walsh (p 232) recommended the American scheme. This latter could be readily introduced into Britain by offering two places where the doctor could sign the Health Service prescription: those signing on the left would expect the proprietary drug to be supplied, while those signing on the right would permit the pharmacist to dispense the generic equivalent.
I am considering, however, having all my FP10 NHS prescription forms overstamped with "The generic equivalent may be supplied," and would value guidance from readers on the ethical and legal aspects of such a stamp.

\section{London NW10 5UY}

Ronald LAW

\section{Treatment of axillary hyperhidrosis}

SIR,-We are rather concerned that the report by Mr C R W Rayner and others (10 May, p 1168) may prejudice others against the use of the excellent treatment with $20 \%$ aluminium chloride hexahydrate.

They reported that after two weeks, 24 out of 38 patients had obtained considerable relief, a response rate of over $68 \%$, although five of these patients apparently did not find the treatment acceptable. "After six months, only six out of the original 19 with an effective initial response had sustained relief." What the authors imply here is that six out of this original group who persisted with treatment for two weeks were then free of axillary hyperhidrosis for a further six months without any further treatment. A further nine patients were controlled by twice-weekly applications, and another required treatment only once a fortnight, surely an acceptable frequency of treatment for even the least compliant of patients. It would seem, therefore, that 16 out of the original 38 patients $(42 \%)$ have done rather well.

It would be helpful to know what placebo was used, and whether the $20 \%$ aluminium chloride hexahydrate was dissolved in absolute alcohol as used by Scholes $e t a l,{ }^{1}$ with whose study the authors have compared their results.

We have achieved satisfactory results with outpatients by asking them to apply an aqueous solution of $20 \%$ aluminium chloride hexahydrate twice weekly at night. Using this regimen we have had few complaints of local irritation.

Finally, in comparing a medical treatment with surgery, it would seem only fair to mention the failure rate and possible morbidity and mortality of the procedure described.

Perhaps the most important conclusion that can be drawn from this report is that the treatment of axillary hyperhidrosis should be left to the physicians.

Dermatology Department

W F G TUCKER St Mary's Hospital,

${ }^{1}$ Scholes KT, Crow KD, Ellis JP, Harman RR,
Saiman EM. Br Med $\mathcal{f}$ 1978;ii :84-5.

${ }_{*}^{*}$ We sent this letter to Mr Rayner, whose reply is printed below.-ED, $B M \mathcal{F}$.

SIR,-Unfortunately your correspondent seems to have missed the point of our paper on axillary hyperhidrosis (10 May, p 1168).

Firstly, it was not our intention to deny that aluminium chloride hexahydrate could be effective, and indeed we use it ourselves in some patients with considerable success. Scholes et al suggested that surgery was no longer indicated in this condition and we have identified a group of patients in whom it is still necessary. Secondly, Dr Tucker says that 16 out of 38 patients have done rather well. It is stated quite clearly in our paper that by six months 26 out of 38 patients had opted for surgery-that is, they were given the choice of continuing with the aluminium chloride hexahydrate or having surgery. Thirdly, we stated categorically that our methods were the same as Scholes $e t$ al and thus the aluminium chloride hexahydrate was dissolved in absolute alcohol.

Your correspondent also suggests that we were comparing medical treatment with surgery and again I must say that he does not appear to have read our paper carefully. We very particularly pointed out the differences between our patients and those of Scholes et al. Obviously the two groups were not strictly comparable. The purpose of our paper was to rectify the untrue statement in Scholes's paper that surgery was no longer indicated. With regard to Dr Tucker's point that the treatment of axillary hyperhidrosis should be left to the physicians, I would reply that it would be the utmost pleasure to leave it to them were it not for the fact that there are indeed some patients who require surgery despite their best efforts.

Colin Rayner

\section{Woodend General Hospital,}

Aberdeen AB9 2YS

\section{School screening for scoliosis}

SIR,-Mr Robert A Dickson and his colleagues are to be congratulated on the excellence of their article "School screening for scoliosis" (26 July, p 265), but I think that no work on school screening for scoliosis is complete without some reference to the studies in Greece of Smyrnis, ${ }^{1}$ who reported last year the incidence of the idiopathic type of scoliosis to be $6.2 \%$ among young girls from Evia, whereas it was only $2.5 \%$ amongst similar girls on the island of Lesvos and only $2.4 \%$ on Chios. The implications of this are important alike for those studying the results of school screening (by whatever method) and for those of us who believe that the "idiopathic" type of scoliosis is really congenital in origin.

P A ZORAB

Paediatric Department,

Cardiothoracic Institute

1 Smyrnis P. In: Zorab PA, Siegler D, eds. Scoliosis: proceedings of a sixth symposium. London: Academic
Press, 1980:13-18.

\section{Mild asymptomatic}

hyperparathyroidism

SIR,-We were interested to read the leading article on mild asymptomatic hyperparathyroidism (19 July, p 174). It is obviously difficult to be certain that a case is truly "asymptomatic": many vague symptoms may be overlooked by the patient or may be discounted as being irrelevant to the disease. Yet symptoms such as confusion in the elderly may be caused or exaggerated by primary hyperparathyroidism and are relieved when the disease is cured. ${ }^{1}$ Furthermore, there is a definite risk, however small, of patients with untreated primary hyperparathyroidism developing serious complications such as renal failure ${ }^{2}$ and bone disease. ${ }^{3}$

In skilled hands the risks and postoperative complications of parathyroid surgery are negligible. We therefore feel that surgery is indicated in all cases of primary hyperparathyroidism unless there is a definite contraindication.

With the use of a reliable radioimmunoassay 